\title{
SIMBOLOGIA DO ESTÁVEL NA OBRA DE SAINT EXUPÉRY
}

\author{
("Terre des Hommes", "Vol de Nuit", "Courrier Sud") \\ MIGUELINA SOIFER
}

Um essencial processo de simbolização, fundamentado na atribuição das noções de "eternidade", "permanência", e "realidade" ao "objeto que dura", desenvolve-se no romance saintexupéryano, sendo fàcilmente auscultável na representação figurativa de três ordens de objetos: a pedra, o navio, a árvore.

Estudando este aspecto da criação em Saint-Exupéry, além de fixar-nos numa tendência axial para a gênese da obra, e de trazermos à luz uma faceta da personalidade profunda do escritor. poderemos delimitar de passagem a problemática do símbolo literário, que consistiria, bàsicamente: 1) na descrição do nrocesso associativo; 2) na pesquisa dos motivos da associação; 3) na análise do objeto simbólico como concretizador de determinado simbolismo.

A pedra, incordorada ao cenário do romance através do muro, da casa e do pórtico de pedra, serve frequentemente de ponto de partida à meditação das personagens. Vemos estas personagens procurar obssessivamente, em cenários duráveis, a garantia de sua própria "durabilidade", de sua mesma existência. 0 estranho desejo de cercar-se de objetos e matérias duráveis domina Geneviève, a protagonista de "Courrier Sud". Afastando as tapeçarios, ela acaricia as paredes da casa de Jacques Bernis:

"Por que esconde os muros, Jacques? Porque quer você amortecer o contacto dos dedos e dos muros? Ela gosta de acariciar, com a palma da mão, a pedra; acariciar o que de mais seguro e de mais durável há na casa. Aquilo que pode levar-nos por muito tempo, como um navio" (86 CS) (1).

(1) As cifras remetem à página dos seguintes obras:

$\mathrm{CS}=$ "Courrier Sud" — Libroirie Gallimard, 1929 - Colection Pourpre.

$\mathrm{VN}=$ "Vol de Nuit" - Librairie Gallimard, 1931 - Le Livre de Poche.

$\mathrm{TH}=$ "Terre des ommesHommes" — Librairie Gallimard — 1931 — Le Livre de Poche. 
E o "pórtico de pedras largas" enraizado na terra the aparece como a imagem mesma da "certeza de duração", sentimento de equilibrio perdido para sempre, desde que abandonara a antiga casa:

"Porém essa certeza de duração, não mais a tinha. Pensou: as coisas duravam mais do que eu. Eu era recebida, acompanhada, estava certa de que seria cuidada, e agora vou durar mais do que as coisas /.../ Reviu oquela cosa entre as espessos tílias. Anuilo que aparecia na superfície era o que de mais estável existia: esse pórtico de pedras largas que continuava na terra" ( 86 CS).

As coisas que duram mais do que o homem são "eternas", e fazem o homem participar dessa "eternidade". Assim o sente Fabien, o piloto de "Vol de Nuit" que procura "sua parte de eternidade" entre os jardins fechados por velhos muros:

"Fabien teria desejado viver aqui muito tempo, receber aaui sua parte de eternidade, pois as cidadezinhas onde ficava uma hora e os jardins fechados oor velhos muros. pareciam-lhe eternos por durarem fora dele" (5 VN).

Face a esta necessidade individual de duracõo, qua parece orientar-se para as matérias que duram, o símbolo do templo de Dedras incarnará a eternidade de todo um povo. A pedra atinge, no símbolo do templo, o seu mais largo simbolismo:

"Trata-se de torná-los eternos... "Onde havia lido isso? Aquilo que perseguis em vós mesmos morre". Reviu um templo ao deus Sol, dos antigos incas do Peru. Essas pedras erguidas sobre a montanha. Que restaria sem elas, de uma civilização poderosa aue pesava com o pêso de suas pedras sobre o homem de hoie, como um remorso? Em nome de que crueldade ou de que estranho amor o condutor de povos de outrora, obrigando suas multidōes a puxar esse templo para as montanhas, impôs-lhes de erguer sua eternidade? / .../ $\mathrm{O}$ condutor de povos de outrora, não teve talvez piedade do sofrimento do homem, mas teve piedade, imensamente, de sua morte. Não de sua morte individual, mas piedade da espécie que apagario o mar de areia. E conduzia seu povo erguer pelo menos as pedras que o deserto não enguliria". (123 Vol de Nuit).

O templo de pedras simboliza uma civilização. Em obras posteriores de Saint-Exupéry outras imagens virão ilustrar e pre- 
cisar o conceito, como observa Pierre H. Simon (2): "O palácio, o império, a cidade, obras que, parecidas a navios bem aparelhados, sobrenadam as ondas do tempo, mas são também harmonias de leis, de princípios e de crenças nas quais cada vontade individual integra seus atos em vista de uma finalidade superior justificadora". Mas no símbolo de "Vol de Nuit" aue citamos acima, encontra-se tal insistência no aspecto da durabilidade da obra, que bem podemos perguntar-nos se o que é estimado no símbolo é o patrimônio espiritual da civilização inca, ou simplesmente a obra durável que sobreviverá ao homem:

"... pelo menos pedras que o deserto não soterrará". "Que restaria sem elas de uma civilização poderosa. . ."

Qual seria, entretanto, a razão desta insistente presença fiqurativa da pedra? P. H. Simon observa que "A intuicão nutriente da meditação saintexuperyana é o sentimento agudo, permanente, trágico, da fragilidade do homem, de sua pessoa e de suas criações. Sentimento que, chocando-se com uma ardente exigência de duração, inspira a vontade de orientar a acão sobre aqueles objetos que as forças erosivas do natureza e do tempo poupem relativamente" (2).

A pedra objetivaria assim a matéria que "as forças da natureza e do temno noupam relativamente". satisfazendo a essencial e apaixonada "exigência de duração".

Porém não é sòmente no plano do pensamento, na sua concepção do mundo onde encontraremos a origem desta pungente necessidade de duração: ela tem raizes vivenciais profundas, as únicas passiveis de justificar plenamente a insistente seleção imaginativa que estamos observando em Saint-Exudéry. Uma destor raizes se insere no infância do autor, a segunda na profissão dn adulto. A nostalạia do estável aparece assim como decorrente do forte sentimento de estabilidade familiar que uma infância feliz na casa paterna proporcionou ao sensível Tonio; a mesma tendência, exacerbada pela mobilidade contínua do aviador, crictalizará na idealização do lar, nítida em sua obra. Todos estes matizes explicam a gênese dos símbolos, imagens e temas que estudamos.

Os objetos duráveis tornam-se condição necessária para o mesmo sentimento de existência:

"É preciso ter ao redor, para existir, realidades duráveis" (82 CS).

(2) Simon, Pierre Henri - "L'Homme en procès", paginas 130-131, e 126.

Neuchâtel, A la Bacconière, 1950. 
Sem um cenário sólido, sem referências concretas, corre-se - risco de sentir a vida como "uma sucessão de espetáculos não necessários e um pouco mais reais que os de um livro" (90 CS). Assim vemos esboçar-se no romance o tema da "casa sólida". A casa sólida e tudo quanto ela contém de durável, como as "mesas maciças que poderiam atravessar os séculos sem sair de moda nem envelhecerem" serão garantias de existência, de eternidade, para o homem demasiado consciente de sua fragilidade.

A casa - eterna - torna-se também um templo na evocação do narrador de "Courrier Sud":

"Eu revia os grandes armários solenes da casa... A veIha governanta trotava como um rato de um para outro, sempre conferindo, desfraldando, dobrando, recontando a ro upa branca, exclamando: "Ah, meu Deus, que infelicidade !", a cada sinal de desgaste que ameaçasse a eternidade da casa, correndo depressa queimar os olhos sob a lâmpada para reparar a trama daquelas toalhas de altar, para serzir essas velas de três mastros, servindo não sei que coisa maior que ela, um Deus ou um navio" (85 TH).

E assim que é introduzido outro dos símbolos do eterno em Saint Exupéry: o do navio. Este símbolo é determinado pelas noções "objeto que dura" e que "sobrenada as ondas do tempo"; guardando o simbolismo da pedra transmitido ao muro e à casa, produz-se a interferência dos objetos "casa" e "navio":

"Ela gosta de afagar, com a palma da mão, a pedra; acariciar o que há de mais seguro e de mais durável na casa. Aquilo que pode levar-nos durante muito tempo, como um navio" (86 CS).

$E:$

"Sua casa era um navio. Pa ssava as gerações de uma margem a outra" (105 CS).

". . a casa que estala ao vento está ameaçada como um navio" (154 CS).

Outra noção determinante do mesmo símbolo é a de "Arca de Noé", que reune os noções "objeto durável" e "objeto que pode levar-nos por muito tempo"; enquanto tudo desaparecia da superfície terrestre, só a Arca subsistia: ela é assim uma imagem perfeita do "eterno". O navio, neste caso, é antes de tudo o objeto que "sobrenada as ondas do tempo".

$\mathrm{E}^{\prime}$ numo passagem de "Lettres à sa mère" onde encontramos a referência implícita: 
Primeiras chuvas. Um pequeno fio de água escorre sobre o nariz quando a gente faz a sesta. O céu faz correr, fora, bancos de nuvens. A barraca aberta ao vento tem suas queixas de navio, e como chuva fez grandes lagos ao redor dela, dir-se-ia a Arca de Noé (3).

Se o aviāo é comparado a um navio, o é por ser um recinto fechado e calmo, onde os passageiros experimentam o prazer de se sentirem protegidos, enquanto que os perigos ameaçadores sucedem-se fora, qualidade inerente também à casa:

"E nós jogamos, fechados, bem aquecidos, no porão de nosso navio, enquanto lá fora redobram explosões semelhantes a golpes de mar" (244 TH).

Uma sensação calmante de segurança, durante a viagem sem sentido que é a vida, será experimentada ao aconchego da casa-navio:

"Sua casa era um navio. / . . / A viagem não tem sentido, nem aqui, nem além, mas que segurança sentimos por termos nossa passagem, nossa cabina, nossas malas de couro amarelo. Por termos embarcado..." (105 CS).

Paralelamente à nostalgia do estável, este comprazer-se no aconchego, na segurança do recinto fechado, seja este casa ou aviāo, é particularmente significativo.

Dentro da idealização do lar antes mencionada, e numa sugestão plenamente religiosa, casa e navio designarão moradia de Deus, a igreja:

"Que será de vós fora de minha morada, fora deste navio onde a passagem das horas toma seu pleno sentido, como sob a quilha reluzente o escoar do mar ?" (112 CS).

O simbolismo mais amplo da imagem do navio é atingido, sempre dentro da significação de morada, quando a imagem é oplicada ao planeta Terra, no momento em que o aviador inebriado, sente-se "amarrado à Terra". A gravidade do tom, a solenidade do ritmo no parágrafo que citaremos, e na atitude do protagonista, alongado "dos calcanhares à nuca" sôbre a terra, revelam a profundidade da tendência que estudamos, tendência, aliás, básica na gênese da obra "Terra dos Homens" refletida já no próprio título, e que talvez nunca anteriormente tenha sido exprimida com tanta autenticidade, como quando ao escritor une-se o aviador:

(3) Antoine de Saint-Exupéry — "Lettres à sa mère" — Gallimard, Paris, 1955, página 106. 
"Descobria-me aplicado a meu astro por uma pesantez semelhante àquela que na curva nos liga a um carro, e gozei esse estreitamento admirável, essa solidez, essa segurança. Adivinhei, sob o meu corpo, a ponte de meu navio. / . . / Eu sentia bem que habitava esta pátria /.../ (82 TH).

Pela sua sugestão de eternidade o símbolo adquirirá a mesma transcendência da pedra no templo de pedras dos Incas. Como pela pedra, os homens "duram pelo seu navio":

"Ele (Rivière) pensou nas cidadezinhas de outrora, que ouviam falar das ilhas e construiam um navio. Para corregá-lo com sua esperança. Para que os homens pudessem ver a esperança desfraldar velas sôbre o mar. Todos engrandecidos, todos transcendidos, todos liberados por um navio. O fim talvez nada justifica, mas a ação liberta da morte. Estes homens duram pelo seu navio" (152 VN).

Não só o caráter de "eternidade" é atribuido oo material durável; outras noçōes lhe são associadas: "evidência", "realidade", "imobilidade". Ao aviador em confronto habitual com o mundo da transitoriedade e do movimento, na incessante experiência do efêmero, um muro sôbre a terra pode bem figurar a imagem da evidência, da realidade:

"Ele (o aviador após o descenso) toca já um muro eterno..." (158 CS).

"Um velho muro ruindo e carregado de hera. Ressequido, penetrado, moldado de sol, moldado de evidência" (149 CS).

"Motor em diminuição, o mergulho rumo a esse fundo de mar onde tudo repousa, onde tudo toma a evidên cia e a duração de um muro" (43 CS).

O imóvel guarda tanto a sugestão de evidência, de realidade, quanto de "eternidade". A imobilidade do morto é associada à sua "eternidade":

Desaparecidos? (os mortos) Quando entre aqueles que são cambiantes só êles são duráveis? Quando seu último rosto era tão verdadeiro que nada dêles poderá jamais desmenti-lo...! (89 CS).

A procura do imutável pode dar lugar a outro movimento psicológico motivado também por umo dolorosa consciência do fragilidade humana: irritação contra a vida que é contínuo movimento, transcurso constante, efêmero: 
"Que tenho eu a fazer aqui, eu, vivo, entre êstes mármores incorruptiveis? Eu, perecível, cujo corpo se dissolverá, que tenho a fazer aqui, na eternidade...? (185 TH).

O mágico caráter de realidade e de evidência que o aviador descobria num muro de pedras incarna também na árvore:

"Por dez minutos mistura-se a uma discussão que não entende, a gestos que se iniciam, que se concluem. É irreal esta visão. Porém uma árvore plantada diante da porta resiste há mais de trinta anos. Há trinta anos fornece uma imagem" (3 I CS).

A árvore comunica à paisagem a sugestão de imobilidade que caracteriza as coisas "eternas":

"As árvores permaneciam imóveis, prêsas suas ramas na cola do crepúsculo" (115 CS).

Esta aspiração ao imutável aparece claramente como uma forma de evasão, e orienta a transfiguração operada no plano imaginativo; também orienta a transformação bem observada por Leon Werth (4):

"Suas imagens sõo mais frequentemente de uma pureza calma. Faz poucas alusões à velocidade. E ainda acontece que ele transforma a velocidade em imobilidade".

A recusa da velocidade em favor da imobilidade é paralela portanto à evasão no imutável e talvez ambas tendências estejam relacionadas com outro fato notável: a raridade da alusão a certas noções científicas que constituem evidência ineludivel na experiência diária do aviador: curso do tempo, relatividade do mundo real, a vida como "devenir" e constante mobilidade, o espaço-tempo, etc. Situamos uma só alusão a espaço e tempo dentro da perspectiva einsteiniana:

"Port Etienne, primeira escala, não está inscrita no espaço, mas no tempo, e Bernis olha seu relógio. /.../ Bernis olha o relógio pelo qual se opera tal milagre. Depois o ponteiro imóvel. Se esta agulha perder seu número, se a "panne" entregar o homem à areia, o tempo e a distância tomarão um sentido novo que êle nem sequer concebe. Viaja numa quarta dimensão". (169 CS).

(4) Werth, Léon: "La vie de Saint-Exupéry", Editions du Seuil, 1948, página 179. 
A dialética saintexuperyana em torno ao tópico "eternidade" poderia "simbolizar-se" na meditação do viajante de trem, em "Courrier Sud":

"Cada segundo suportado lança para trás casas, bosques, vilas. Porém se abrirmos os olhos, do nosso lugar vemos sòmente um anel de cobre, sempre o mesmo. Transformamo-nos sem o saber" (85 CS).

Saint Exupéry parece levado a desconhecer o tempo ("cada segundo"), o espaço ("casas, florestas, aldeias"), o mesmo devir ("transformamo-nos sem sabê-lo"), para fixar obstinadamente o olhar sôbre este objeto imóvel e imutável, este anel de cobre ("sempre o mesmo") no qual reconhece ao menos uma imagem da eternidade que persegue. Tal atitude, ao eludir qualquer perspectiva científico-filosófica para resolver-se num imediatismo primário (é eterno aquilo que dura) lembro as associações da imaginação primitiva. Com efeito, a pedra, simbolisando eternidade, era odorada pelos primitivos, que lhe reconheciam também o poder de transmitir sua incorruptibilidade (5).

A não duvidar, uma tendência marcante em Saint Exupèry poderia estudar-se partindo do rótulo "anti-intelectualismo".

Quanto à conclusão sôbre o natureza e as funções do símbolo literário no romance, observamos que o processo associativo, dentro da interpretaçāo tradicional, é a conexão de uma noção abstrata - "eternidade" ou "permanêncio" ou "realidade" com objetos concretos, simples, (pedra, árvore). Estés objetos devem integrar-se naturalmente nos cenários onde as personagens romanescas se movem. Assim, o simbolismo da pedra é inserido no "muro", no "pórtico", nas "paredes" da casa, na "casa". A noção de "realidade" ou a de "eternidade" incarna na "árvore" (da rua, do jardim).

Quando mais de um conceito (dois ou três) combinam-se num só objeto, ou quando ao conceito fundamental se sobrepõem conceitos metofóricos, nasce a imagem simbólica. Exemplo de imagem simbólica é, aqui, a determinada por: a) o conceito fundamental "objeto que dura"; b) o segundo conceito "ob-

(5) Na caracterização psicológica da personagem Geneviève comprovamos, ao lado da "primitiva" adoraçäo da pedra (Geneviève acariciando os muros da cosa), sua supersticiosa adoraçāo do luminoso e dourado, que notávamos em nosso estudo "O Cromatismo em três Obras de Saint-Exupéry" - in "Humanitas". Anuário (1962-1963) do Foculdade de Filosofia da Universidade Católica do Paraná, páginas 127-135: "Os objetos luminosos, bem como os dourodos, logrom certo poder protetor, mágico, talismânico, como no caso de Geneviève, que ongustioda pela enfermidade do filho, buscará cercar-se de "realidades claras na superfície" (página 131 ). 
jeto que serve de morada ao homem" ou "que pode levá-lo por muito tempo"; c) o conceito metafórico "objeto que sobrenada as ondas do tempo", isto é: navio.

Quanto às causas da associação as encontramos na consciência pungente da fragilidade humana, e, no plano vivencial, no devotamento ao estável, tendência profunda da infância defraudada pela profissão do adulto.

O caráter de imediatismo da associação ("é eterno aquilo que dura") decorre daquilo que, sob uma denominação que abrangeria muitos aspectos da imaginação do autor (símbolos místicos, imagens feéricas, etc.), qualificaríamos de anti-intelectualismo saint-exuperyano. 